\title{
Peak oxygen uptake differentiates competitive from recreational male surfboard riders
}

\author{
Nuno Almeida1,2*, Joana Reis ${ }^{1,2,3}$, João Beckert4 ${ }^{4}$, Miguel Moreira2,5, Francisco Alves ${ }^{1,2}$ \\ ORIGINAL ARTICLE
}

\begin{abstract}
The purpose of this study was to verify if competitive performance status was associated to different levels of specific aerobic fitness in Portuguese surfboard riders. Six recreational surfers (age: $32.3 \pm 3.1$ years; body mass: $73.2 \pm 7.8 \mathrm{~kg}$; height: $1.75 \pm 0.05 \mathrm{~m}$ ) and six competitive international level surfers (age: $25 \pm 8.4$ years; body mass: $68.5 \pm 3.8 \mathrm{~kg}$; height: $1.74 \pm 0.05 \mathrm{~m}$ ) performed a maximal continuous incremental paddling test consisting of two-minute steps starting at $20 \mathrm{~W}$, with increments of $10 \mathrm{~W}$, for determination of peak oxygen uptake and maximal aerobic power. Ventilatory threshold and respiratory compensation point with corresponding heart rate and power output were also determined. Elite surfers presented higher values for peak oxygen uptake $\left(43.6 \pm 7.9 \mathrm{ml} \cdot \mathrm{kg}^{-1} \cdot \mathrm{min}^{-1}\right)$ than recreational surfers $\left(31.1 \pm 7.4 \mathrm{ml} \cdot \mathrm{kg}^{-1} \cdot \mathrm{min}^{-1}, \mathrm{p}=0.01\right)$ however, there were no differences $(p>0.05)$ between groups for maximal aerobic power (elite: $76.6 \pm 18.6 \mathrm{~W}$; recreational: $76.6 \pm 16.6 \mathrm{~W})$. No significant differences between the power output at which ventilatory threshold or respiratory compensation point occurred but elite surfers reached ventilation threshold with $22.5 \pm 5.8 \mathrm{ml} . \mathrm{kg}^{-1} . \mathrm{min}^{-1}$ which was significantly higher than recreational surfers $(16 \pm 3.7$ $\left.\mathrm{ml} \cdot \mathrm{kg}^{-1} \cdot \mathrm{min}^{-1}\right)$. These findings show that elite surfers have higher values of peak oxygen uptake than recreational surfers which suggest a higher aerobic adaptation that may be related to the different amount of exercise volume undertaken.

Keywords: Surf, water activities, oxygen consumption, ventilation, lactic acid.
\end{abstract}

\section{INTRODUCTION}

Surfing has emerged as one of the most popular sports of the last decade and the number of participants has increased dramatically (Loveless \& Minahan, 2010a). Despite the popularity of competitive and recreational surfing there is a lack of research on the physiological characteristics of surfboard riders (MendezVillanueva \& Bishop, 2005).

The activity of surfing (competitive and recreational) is comprised of three major tasks, paddling out from shore, popping up on the surfboard and (actual) wave ridding (Loveless \& Minahan, 2010a) which are repeated several times during a surfing session. The analysis conducted by Farley, Harris, and Kilding (2012) showed that competitive surfers spend on average $54 \%$ of their time paddling and only $8 \%$ actually riding waves. This phenomenon had been previously described by other authors in both recreational and competitive settings with similar results (Meir, Lowdon, \& Davie, 1991; Mendez-Villanueva, Bishop, \& Hamer, 2006).

Additionally, the unpredictability of the environment and variables such as equipment conditions as well as physical fitness, psychological, mental aptitude and individual skills are keen to influence surfing performance (Mendez-Villanueva \& Bishop, 2005). However, the real contribution of these variables to different levels of performance is not fully understood. In this sense surfing has been regarded as a high intensity intermittent sport, in which propulsion is provided mainly by the upper body (Mendez-Villanueva \& Bishop, 2005). During this type of exercise, the ability to recover

\footnotetext{
Manuscript received at April 17 ${ }^{\text {th }}$ 2017; Accepted at September 20 2017

${ }^{1}$ CIPER - Faculty of Human Kinetics - University of Lisbon, Lisbon, Portugal

${ }^{2}$ Faculty of Human Kinetics - University of Lisbon, Lisbon, Portugal

${ }^{3}$ Universidade Europeia, Laureate International Universities, Lisbon, Portugal

${ }^{4}$ Faculdade de Ciências Médicas - Universidade Nova de Lisboa, Lisbon, Portugal

${ }^{5}$ SPERT Lab - Faculty of Human Kinetics - University of Lisbon, Lisbon, Portugal

* Corresponding author: Faculdade de Motricidade Humana - Univerisdade de Lisboa. Laboratório de Fisiologia e Bioquímica do Exercício Estrada da Costa 1499 - 002 Cruz Quebrada - Dafundo E-mail: nrcalmeida@gmail.com
} 
from previous work is determinant to performance outcome (Tomlin \& Wenger, 2001; Tschakert \& Hofmann, 2013). Furthermore, aerobic fitness has been shown to be crucial to the recovery processes during this type of exercise (Tomlin \& Wenger, 2001) thus it is surprising that so few studies have addressed this problem in surfing.

Surfboard riding at elite level has been shown to depend on aerobic performance capacity as the lactate threshold (LT) and peak power output ( $\left.\mathrm{W}_{\text {peak }}\right)$ could be suggested to distinguish surfers of different competitive levels (MendezVillanueva et al., 2005; Farley et al., 2012). However, some studies have shown that specific aerobic fitness parameters such as peak oxygen uptake $\left(\mathrm{VO}_{\text {2peak }}\right)$ are not discriminative between surfers of different levels of performance (Loveless \& Minahan, 2010a). Furthermore, recent studies have concluded that $\mathrm{VO}_{\text {2peak }}$ does not relate neither with surfboard performance nor with different levels of expertise in the sport (Farley et al., 2012; Loveless \& Minahan, 2010a, b). A different tendency could be seen regarding the LT which has shown both significant differences ( $\sim 7 \% ; p=0.02)$ between European level competitive surfers and regional level competitive surfers and a positive correlation between LT values and season rank $(r=0.57$; $p=0.03$ ) (Mendez-Villanueva et al., 2005).

To our knowledge, no previous studies were found that address both the peak oxygen uptake and ventilatory parameters relation with different levels of surfing performance in Portuguese surfers providing a better understanding of the factors which unveil the real physiological differences induced by this sport. Thus, the purpose of this study was to measure and compare peak oxygen uptake and ventilation parameters associated with the LT and the respiratory compensation point (RCP) in recreational and competitive Portuguese surfboard riders during paddling ergometry. It was hypothesized that competitive surfers demonstrate higher values of these aerobic parameters than recreational surfers.

\section{METHOD}

\section{Participants}

Twelve male surfers volunteered to participate in the study and were assigned to two groups, one comprising 6 elite competitive international level athletes (ES: mean age $25 \pm 8.4$ years; body mass $68.5 \pm 3.8 \mathrm{~kg}$; height $1.74 \pm 0.05 \mathrm{~m}$ ) and the other composed by 6 recreational surfers (RS: mean age $32.3 \pm 3.1$ years; body mass $73.2 \pm 7.8 \mathrm{~kg}$; height $1.75 \pm 0.05 \mathrm{~m}$ ) (Table 1). The ES were considered for this group if they had competed both in the national championship and at least in one or more events of the World Qualifying Series (WQS) in the previous year and trained at least 7 sessions a week. The RS were considered for this group if they had been surfing for at least 5 years and at least 2 sessions a week, but had never participated in any surfing competition. Informed consent was obtained from all participants as well as their parent or guardian if they were under 18 years of age.

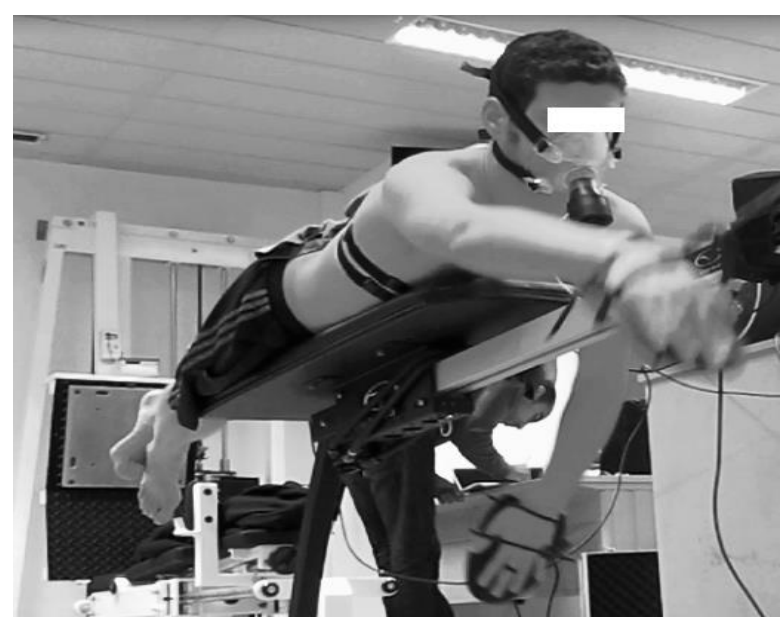

Figure 1. Example of the experimental setup

\section{Measures}

A VASA swim ergometer with Power Meter (VASA, Inc., Essex Junction, VT, and USA) was used in the present study. The ergometer was modified in a way that the bench could not slide (stationary ergometer) and consisted of two hand paddles attached to two pull ropes that induced rotation of the resistance (Figure 1). The external power output of the hand paddles was determined by two force transducers on each. 
The power output of each step of the test was continuously provided to the athlete via a digital display unit and by verbal feedback. The flywheel was set to the minimum resistance to avoid accelerated local muscular fatigue.

\section{Procedures}

The participants were first familiarized with all the equipment and procedures. Subsequently anthropometric measures were assessed (body mass, height). Previous to the incremental test the subjects performed a standardized warm-up consisting of 3 minute of light paddling up to 25 $\mathrm{W}$ at will, combined with three 5-seconds maximal intensity performed every minute followed by active rest, followed by a 5 -minute rest.

All subjects performed a maximal continuous incremental paddling test consisting of twominute steps starting at $20 \mathrm{~W}$, with increments of $10 \mathrm{~W}$, until volitional exhaustion, on a VASA trainer ergometer, for determination of peak oxygen uptake $\left(\mathrm{VO}_{\text {2peak }}\right)$, and maximal aerobic power (MAP). Ventilatory threshold (VT) and respiratory compensation point (RCP) with corresponding heart rate and power output were estimated. Athletes were free to choose their paddling rate and received immediate visual and verbal feedback of the power relative to each step as they were asked to stay within $\pm 5 \mathrm{~W}$ of the required power for each step.

$\mathrm{VO}_{\text {2peak }}$ was considered when the athlete reached volitional exhaustion, was unable to maintain the required power or was unable to sustain the given power for at least one minute in the last stage.

The VT was calculated by v-slope method (i.e., disproportioned increase in carbon dioxide uptake relative to oxygen uptake) as described by Beaver, Wasserman, and Whipp (1986) and the same for RCP by the ventilatory equivalent for $\mathrm{VO}_{2}$ as described by Beaver et al. (1986).

Respiratory data were collected breath by breath (Metamax 3B, Cortex, Biophysik, Leipzig, Germany). Breath-by-breath oxygen uptake values were averaged over $10 \mathrm{~s}$ with peak oxygen uptake taken as the highest 30s oxygen uptake value. The $\mathrm{VO}_{2}$ values of each step were calculated using mean (and standard deviation) of the last 30s of each step. The gas analyser was calibrated before each test using a $3 \mathrm{~L}$ syringe (Hans Rudolph, Kansas City, MO, USA) for known oxygen and carbon dioxide concentration $\left(\mathrm{O}_{2}-15 \% ; \mathrm{CO}_{2}-5 \%\right.$; $)$ according to the manufacturer's instructions. Heart rate (HR) was monitored throughout the test and later (Polar RS800; Kempele, Finland).

All tests were performed at a similar temperature $\left(21^{\circ} \mathrm{C}-25^{\circ} \mathrm{C}\right)$ and within at least 2 hours after the subject's last meal. All subjects were asked to avoid the consumption of coffee and alcohol and physical activity (training) 24 hours before the test.

\section{Statistical Analysis}

All statistical analyses were conducted using a statistical package (IBM-SPSS 19. USA). All group data were reported as means and standard deviation and the statistical significance was set at $p=0.05$. The normality of the population was checked using the Shapiro-Wilk or KolmogorovSmirnov test. After checking the equality of variance using the Levene test, an independent $t$ test was used to test for group differences (whenever the normality of the population was assumed) in physical characteristics (height, body mass) and surfing frequency as well as, $\mathrm{VO}_{\text {2peak, }}, \mathrm{W}_{\text {peak }}, \mathrm{VT}, \mathrm{RCP}$ and percentage of $\mathrm{VO}_{2}$ at which VT and RCP occurred and the nonparametric Mann-Whitney test whenever the normality was not assumed (age). Additionally, the calculation of the effect size was performed to determine the magnitude of the differences between groups (Sullivan \& Feinn, 2012). The effect size index used was Cohen's term " $d$ " which classifies effect sizes as small $(d=0.2)$, medium ( $d$ $=0.5)$, and large $(d \geq 0.8)$.

\section{RESULTS}

\section{Anthropometry and Surfing Frequency}

There were no differences $(p>0.05)$ between competitive surfers and recreational surfers regarding physical characteristics (body mass: $p$ $=0.214$; height: $p=0.528)$ and age $(p=0.199)$ (Table 1).

However competitive surfers show significantly $(p=0.01)$ higher values of sessions 
per week ( $7.7 \pm 1.5$ sessions) than recreational surfers (3.67 \pm 0.8 sessions) (Table 1$)$.

Table 1

Physical characteristics and surfing frequency of recreational and elite surfboard male riders

\begin{tabular}{lccc}
\hline & RS n=6 & ES & $p-$ \\
\hline Age (years) & $32.3 \pm 3$. & $25 \pm 8$. & 0.19 \\
Body mass (kg) & $73.2 \pm 7$. & $68.5 \pm$ & 0.21 \\
Height (m) & $1.75 \pm 0$. & $1.74 \pm$ & 0.52 \\
Surfing Frequency & $3.67 \pm 0$. & $7.7 \pm 1$. & 0.00 \\
\hline
\end{tabular}

$\overline{\text { ES- elite surfers; RS - recreational surfers; *Significantly }}$ different to elite surfboard male riders, $\rho<0.05$.

\section{Incremental Paddling Test Results}

The relative peak oxygen uptake was significantly different $(p=0.01)$ between ES (43.67 $\left.\pm 7.94 \mathrm{ml} \cdot \mathrm{kg}^{-1} \cdot \mathrm{min}^{-1}\right)$ and RS (31.17 \pm 7.44 $\left.\mathrm{ml} \cdot \mathrm{kg}^{-1} \cdot \mathrm{min}^{-1}\right)$ as well as the relative oxygen uptake at which VT occurred $(p=0.04)$ was higher in the ES group $\left(22.5 \pm 5.89 \mathrm{ml} . \mathrm{kg}^{-1} \cdot \mathrm{min}^{-}\right.$ $\left.{ }^{1}\right)$ than in the RS group $\left(16 \pm 3.74 \mathrm{ml} \cdot \mathrm{kg}^{-1} \cdot \mathrm{min}^{-1}\right)$. However no significant differences were found between ES and RS for relative oxygen uptake at which RCP occurred (ES: $33.83 \pm 10.38 \mathrm{ml}^{-\mathrm{kg}^{-}}$ ${ }^{1} \cdot \mathrm{min}^{-1}$; RS: $23.67 \pm 6.37 \mathrm{ml} \cdot \mathrm{kg}^{-1} \cdot \mathrm{min}^{-1}$ ) (Fig. 2).

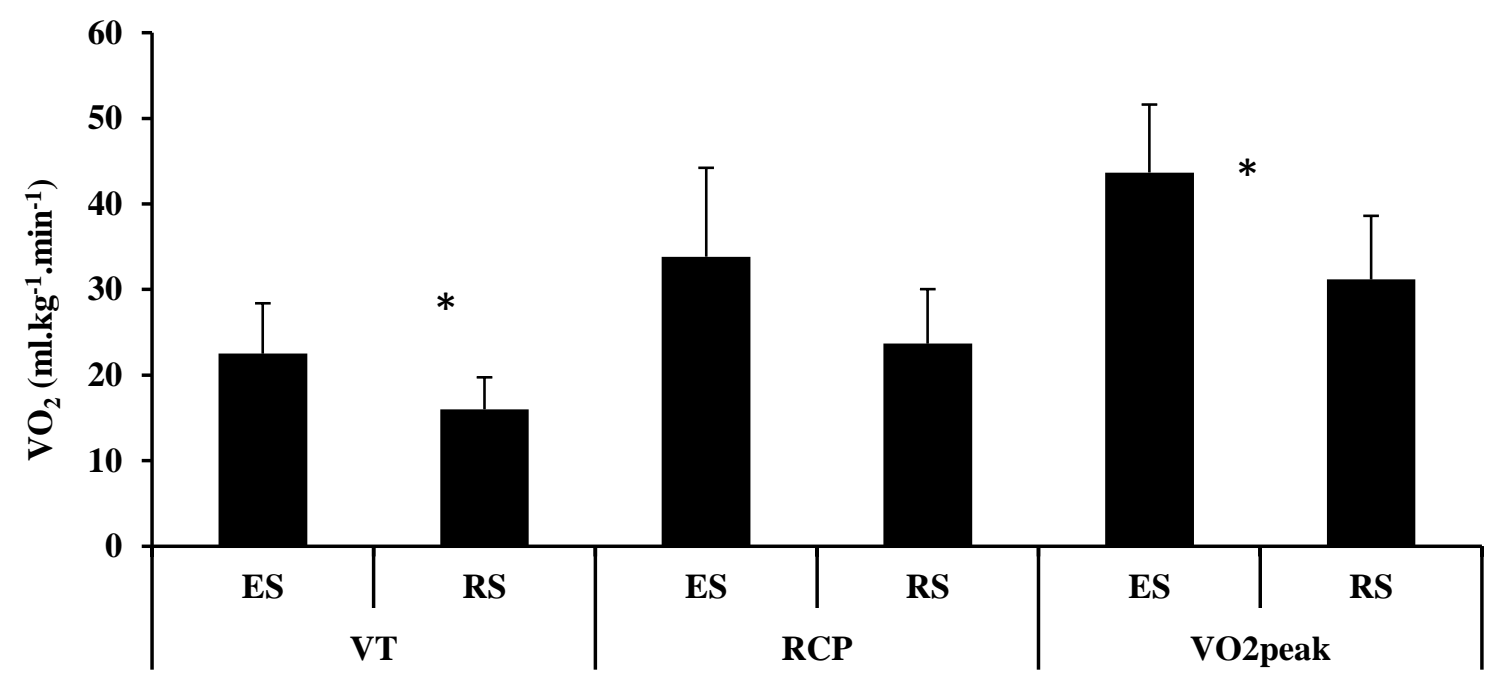

Figure 2. Values of oxygen consumption (ml.kg-1.min-1) of recreational (RS) and elite surfers (ES) at given intensities (VT - ventilatory threshold, RCP - respiratory compensation point; VO2peak - peak oxygen uptake). *Significantly different to elite surfboard male riders, $p<0.05$

Table 2 illustrates the differences between power output, oxygen uptake and the percentage of $\mathrm{VO}_{\text {2peak }}$ at which both thresholds occurred. There were no differences $(p=1)$ between RS and ES for MAP (ES: 76.67 $\pm 18.62 \mathrm{~W}$; RS: $76.67 \pm 16.63 \mathrm{~W})$ nor for the power output at which VT (ES: 50.3 $\pm 12.85 \mathrm{~W}$; RS: 46.32 \pm $8.99 \mathrm{~W}$ ) and RCP (ES: 79.73 $\pm 14.37 \mathrm{~W}$; RS: $75.48 \pm 11.42 \mathrm{~W})$ occurred. These parameters also occurred $(p=0.194)$ at a similar $\% \mathrm{VO}_{2 \text { peak, }}$ $51.5 \%$ and $51.3 \%$ for VT, and $77.5 \%$ and $77.9 \%$ for RCP.

Table 2

Values determined after the incremental paddling test in recreational and elite surfboard male riders (mean $\pm s d)$ (VT Ventilatory Threshold: RCP-Respiratory Compensation Point; MAP - Maximal Aerobic Power; VO2peak - Peak Oxygen Uptake) and effect size measures (Cohen's "d")

\begin{tabular}{lccccc}
\hline & Surfers & ES & RS & $p$-value & $d$ \\
\hline \multirow{2}{*}{ Power Output $(\mathrm{W})$} & $\mathrm{VT}$ & $38.3 \pm 11.7$ & $35 \pm 8.4$ & 0.548 & 0.324 \\
& $\mathrm{RCP}$ & $60 \pm 12.6$ & $56.7 \pm 8.2$ & 0.583 & 0.310 \\
\cline { 2 - 6 } Oxygen Uptake $\left(\mathrm{ml} \mathrm{kg}^{-1} \mathrm{~min}^{-1}\right)$ & $\mathrm{VT}$ & $22.5 \pm 5.9$ & $16 \pm 3.7^{*}$ & 0.046 & 1.319 \\
& $\mathrm{RCP}$ & $33.8 \pm 10.4$ & $23.7 \pm 6.4$ & 0.68 & 1.169 \\
& $\mathrm{VO}_{\text {2peak }}$ & $43.7 \pm 7.9$ & $31.2 \pm 7.4^{*}$ & 0.01 & 1.633 \\
\cline { 2 - 6 } Oxygen Uptake $\left(\% \mathrm{VO}_{\text {2peak }}\right)$ & $\mathrm{VT}$ & $51.7 \pm 10.7$ & $51.6 \pm 4.9$ & 0.194 & 0.012 \\
& $\mathrm{RCP}$ & $72.5 \pm 17.2$ & $75.6 \pm 7.8$ & 0.05 & 0.232 \\
\hline
\end{tabular}

*Significantly different to elite surfboard male riders, $\rho<0.05$. 


\section{DISCUSSION}

The main finding in the present investigation was the fact that ES showed higher values of $\mathrm{VO}_{\text {2peak }}$ which may be related to the amount of time spent training. The protocol accounted for the fact that testing at the same absolute workload determines a given energy demand, emphasizing that training (i.e.: level of performance hence the ES showed significantly higher values of surfing frequency) could alter the substrate oxidation and flux at the same energy demands (Philips, 2006). These results challenge previous studies that reported no differences in $\mathrm{VO}_{\text {2peak }}$ between surfers of different performance levels (Farley et al., 2012; Loveless \& Minahan, 2010a; Mendez-Villanueva et al., 2005). Furthermore, Loveless and Minahan (2010a) found that ES showed significantly higher values of $\mathrm{W}_{\text {peak }}$ than RS which differs from this study (ES: $76.67 \pm 18.62 \mathrm{~W} ; \quad \mathrm{RS}: \quad 76.67 \pm 16.63 \mathrm{~W} ; p$ $>0.05)$.

The results of previous studies have shown lower values than our study for $\mathrm{VO}_{2 \text { peak }}$ measured in arm crank $\left(41.6 \pm 4 \mathrm{ml} \cdot \mathrm{kg}^{-1} \cdot \mathrm{min}^{-1}\right)$ or in tethered swimming $\left(40.4 \pm 2.9 \mathrm{ml} \cdot \mathrm{kg}^{-1} \cdot \mathrm{min}^{-1}\right)$ (Lowdon, Bedi, \& Horvath, 1989). However more recent studies showed the opposite tendency as Meir et. al. (1991) found higher values (54. $\left.2 \pm 10.2 \mathrm{ml} \cdot \mathrm{kg}^{-1} \cdot \mathrm{min}^{-1}\right)$ for RS as well as MendezVillanueva et al. (2005) revealed higher values of $\mathrm{VO}_{\text {2peak }}$ than our study, despite no differences being found between different competitive levels (European level vs. Regional level). Given that the protocols and types of testing were different between studies, the comparison amongst studies must be made with caution. Furthermore, testing in arm crank could cause additional difficulties by different neuromuscular recruitment and by hemodynamic differences between the supine position and sitting position. Moreover, the differences may be related with the number of hours of practice but also with variables related with the local where the surfers usually train. In this sense environmental and coastal changes may induce different types of adaptations (Scarfe, Healy, \& Rennie, 2009), namely in metabolic variables such as oxygen consumption and the ventilatory thresholds.
These coastal changes have been shown to be quite distinct among locations. Lowdon et al. (1989) referred 2 minutes of paddling out to the take-off area whereas Mendez-Villanueva et al. (2006) have found more than 4 minutes of paddling in a different location.

Ventilation's behaviour during incremental exercise describes theoretically 2 transition points usually referred to as first $\left(\mathrm{VT}_{1}\right)$ and second ventilatory thresholds $\left(\mathrm{VT}_{2}\right)$ (Meyer, Lucia, Earnest, \& Kindermann, 2005; Pires, Hammond, Lima-Silva, Bertuzzi, \& Kiss, 2011; Wasserman, Whipp, Koyl, \& Beaver, 1973). The first ventilatory threshold relates to the exercise intensity at which blood lactate starts to accumulate above resting values and has been shown to be a good predictor of endurance performance and good indicators of high level of endurance training (Jones \& Carter, 2000). The buffering of this metabolic acidosis increases $\mathrm{CO}_{2}$ and $\mathrm{H}^{+}$concentrations, causing an increase of $\mathrm{PCO}_{2}$. With increased tissue metabolism and insufficient alveolar ventilation pulmonary ventilation is stimulated (Barrett, Barman, \& Boitano, 2010; Beaver et al., 1986; Wyatt, 1999). The present study found higher values for oxygen uptake at the VT for ES group. Although no differences were found for power output or $\% \mathrm{VO}_{2 \text { peak }}$ at which VT occurred, these values were always higher in the ES group.

Several authors have described that training at VT intensity could present the best alternative for improving endurance as this type of training could induce the necessary adaptations without the time limiting factors of metabolite accumulation (Weltman, Snead, Stein, Seip, Schurrer, \& Rutt, 1990; Weltman, 1995). Several studies have shown that increases in training intensity or training until exhaustion is accompanied by a decrease in motor ability and reduction of postural control. For these reasons higher values of VT may delay the onset of fatigue and preserve psychomotor skills therefore reducing errors (Guidetti, Franciosi, Gallotta, Emerenziani, \& Baldari, 2011; MendezVillanueva, et al., 2005; Paillard, Margnes, Portet, \& Breucq, 2011). Our study supported the fact that higher values of LT may delay fatigue and its 
effects on performance outcome. Probably ES are able to delay the effects of fatigue therefore preserving the coordinative and motor skills essential to surfing and reducing the occurrence of errors that can lead to poor decisions that influence the outcome on competition (MendezVillanueva \& Bishop, 2005). Accordingly, the exercise intensity or duration to fatigue has been shown to be accompanied by a reduction motor ability and psychomotor skills (Guidetti et al., 2011; Paillard et al., 2011).

On the other hand, no differences were found for oxygen uptake at the RCP (VT2) but once again a tendency for higher values in ES for $\mathrm{VO}_{2}$ and power output was found. It has been previously described that exercise at the RCP increases postural instability (Guidetti et al., 2011). However, that study was conducted on a treadmill which can influence visual, vestibular and somatic sensors affecting the postural control (Nagy, Toth, Janositz, Kovacs, Feher-Kiss, \& Angyan, 2004). Our study contradicts the data by Mendez-Villanueva et al. (2005) which reported higher values of $\mathrm{LT}_{4}$ (exercise intensity at which blood lactate concentration reaches a concentration of $4 \mathrm{mmol} . \mathrm{L}^{-1}$ ) and an inverse correlation between the $\mathrm{LT}_{4}$ and ranking position.

The main limitations of this study were the reduced number of subjects in the sample and number of sessions of training per week which place both groups at a different starting point (however the purpose of the study was to clarify the differences between groups). Additionally, the absence of differences between the groups regarding power output may indicate that this test protocol is not specific enough to account for muscular performance changes, moreover when paddling is (still) considered secondary to surfing competitive performance outcome. Further studies should be conducted in a more ecological situation, preferentially involving actual water board paddling.

\section{CONCLUSION}

Our findings highlight that ES developed physiological adaptations, namely higher values of $\mathrm{VO}_{\text {2peak }}$ than $\mathrm{RS}$ which highlights a higher aerobic adaptation that may be related to the different amount of exercise volume undertaken.
Furthermore, our study seems to support that higher values of LT may delay fatigue and its effects on performance outcome, since ES presented higher values of this physiological parameter. However, research on the physiological profile of surfers is still scarce and further investigation is needed.

Acknowledgments:

Nothing to declare.

Conflict of interests:

Nothing to declare.

Funding:

Nothing to declare.

\section{REFERENCES}

Barrett, K. E., Barman, S. M., \& Boitano, S. (2010). Ganong's review of medical physiology: New Delhi: McGraw Hill, 2010.

Beaver, W. L., Wasserman, K., \& Whipp, B. J. (1986). A new method for detecting anaerobic threshold by gas exchange. Journal of Applied Physiology, 60(6), 2020-2027.

Farley, O., Harris, N. K., \& Kilding, A. E. (2012). Anaerobic and aerobic fitness profiling of competitive surfers. The Journal of Strength $\mathcal{E}$ Conditioning Research, 26(8), 2243-2248.

Farley, O. R., Harris, N. K., \& Kilding, A. E. (2012). Physiological demands of competitive surfing. The Journal of Strength \& Conditioning Research, 26(7), 1887-1896.

Guidetti, L., Franciosi, E., Gallotta, M. C., Emerenziani, G. P., \& Baldari, C. (2011). Postural control after a prolonged treadmill run at individual ventilatory and anaerobic threshold. Journal of Sports Science and Medicine, 10, 515-519.

Jones, A. M., \& Carter, H. (2000). The effect of endurance training on parameters of aerobic fitness. Sports Medicine, 29(6), 373-386.

Kenney, W. L., Wilmore, J., \& Costill, D. (2015). Physiology of Sport and Exercise (6 $6^{\text {th }}$ Ed.). Champaign, IL: Human kinetics.

Loveless, D. J., \& Minahan, C. (2010a). Peak aerobic power and paddling efficiency in recreational and competitive junior male surfers. European Journal of Sport Science, 10(6), 407-415.

Loveless, D. J., \& Minahan, C. (2010b). Two reliable protocols for assessing maximal-paddling performance in surfboard riders. Journal of Sports Sciences, 28(7), 797-803.

Lowdon, B., Bedi, J., \& Horvath, S. (1989). Specificity of aerobic fitness testing of surfers. The Australian Journal of Science and Medicine in Sport, 21 (4), 7-10. 
Meir, R. A., Lowdon, B., \& Davie, A. J. (1991). Heart rates and estimated energy expenditure during recreational surfing. The Australian Journal of Science and Medicine in Sport, 23 (3), 70.

Mendez-Villanueva, A., \& Bishop, D. (2005). Physiological aspects of surfboard riding performance. Sports Medicine, 35(1), 55-70.

Mendez-Villanueva, A., Bishop, D., \& Hamer, P. (2006). Activity profile of world-class professional surfers during competition: a case study. Journal of Strength and Conditioning Research, 20(3), 477-482.

Mendez-Villanueva, A., Perez-Landaluce, J., Bishop, D., Fernandez-Garcia, B., Ortolano, R., Leibar, X., et al. (2005). Upper body aerobic fitness comparison between two groups of competitive surfboard riders. Journal of Science and Medicine in Sport, 8(1), 43-51.

Meyer, T., Lucia, A., Earnest, C. P., \& Kindermann, W. (2005). A conceptual framework for performance diagnosis and training prescription from submaximal gas exchange parameters: theory and application. International Journal of Sports Medicine, 26(S1), S38-S48.

Nagy, E., Toth, K., Janositz, G., Kovacs, G., Feher-Kiss, A., Angyan, L., \& Horvath, G. (2004). Postural control in athletes participating in an ironman triathlon. European Journal of Applied Physiology, 92(4-5),

407-413. https://doi.org/10.1007/s00421-004-1157-7

Paillard, T., Margnes, E., Portet, M., \& Breucq, A. (2011). Postural ability reflects the athletic skill level of surfers. European Journal of Applied Physiology, 111(8), 1619-1623.

Pendergast, D., Cerretelli, P., \& Rennie, D. (1979). Aerobic and glycolytic metabolism in arm exercise. Journal of Applied Physiology, 47(4), 754760.

Philips, S. (2006). Endurance training-induced adaptations in substrate turnover and oxidation. Exercise Metabolism, 187-213.
Pires, F. O., Hammond, J., Lima-Silva, A. E., Bertuzzi, R. C., \& Kiss, M. A. P. (2011). Ventilation behavior during upper-body incremental exercise. The Journal of Strength \& Conditioning Research, 25(1), 225-230.

Scarfe, B. E., Healy, T. R., \& Rennie, H. G. (2009). Research - based surfing literature for coastal management and the science of surfing-a review. Journal of Coastal Research, 25(3), 539-557

Sullivan, G. M., \& Feinn, R. (2012). Using Effect Size - or Why the $p$ value is not enough. Journal of Graduate Medical Education, 4(3), 279-282.

Tomlin, D. L., \& Wenger, H. A. (2001). The relationship between aerobic fitness and recovery from high intensity intermittent exercise. Sports Medicine, 31(1), 1-11.

Tschakert, G., \& Hofmann, P. (2013). High-intensity intermittent exercise: methodological and physiological aspects. International Journal of Sports Physiology and Performance, 8(6), 600-610.

Wasserman, K., Whipp, B. J., Koyl, S., \& Beaver, W. (1973). Anaerobic threshold and respiratory gas exchange during exercise. Journal of Applied Physiology, 35(2), 236-243.

Weltman, A. (1995). The blood lactate response to exercise. Champaign, IL: Human Kinetics.

Weltman, A., Snead, D., Stein, P., Seip, R., Schurrer, R., Rutt, R., \& Weltman, J. (1990). Reliability and validity of a continuous incremental treadmill protocol for the determination of lactate threshold, fixed blood lactate concentrations, and VO2max. International Journal of Sports Medicine, 11 (1), 26-32. https://doi.org/10.1055/s-20071024757

Wyatt, F. B. (1999). Comparison of lactate and ventilatory threshold to maximal oxygen consumption: a meta-analysis. The Journal of Strength \& Conditioning Research, 13(1), 67-71.

All content of Journal Motricidade is licensed under Creative Commons, except when otherwise specified and in content retrieved from other bibliographic sources. 